\section{Amplification of Differen- tially Displayed PCR Products Isolated from Untreated Denaturing Polyacrylamide Gels}

BioTechniques 22:240-244 (February 1997)

Analysis of differentially expressed genes has been facilitated by introduction of two related techniques: differential display $(3,4)$ and RNA arbitrarily primed polymerase chain reaction (RAP-PCR) (10). These powerful techniques have been used to identify developmentally, environmentally and hormonally regulated genes in animals and plants (5,7-9). In each method, two or more RNAs are used as templates to generate cDNA. Subsequently, the cDNA fragments are amplified by PCR using an arbitrary primer in the presence of a radiolabeled dNTP. After separation by denaturing polyacrylamide gel electrophoresis, the gels are fixed and dried. Differentially amplified cDNAs are identified by autoradiography. To produce sufficient DNA for further analysis, the differentially expressed DNA must be eluted from the gel and re-amplified in a second, highstringency PCR. This last step has proven to be problematic for researchers, with poor yields of re-amplified product being common. Two solutions to the problem have been purification of the eluted DNA by ethanol precipitation or addition of a third high-stringency PCR. We present an alternative solution, which consistently gives high yields of DNA in the second round of $\mathrm{PCR}$ and requires fewer manipulations of the gel.

RAP-PCR was done according to the manufacturer's protocol (Stratagene, La Jolla, CA, USA) using either [ $\left.{ }^{32} \mathrm{P}\right] \mathrm{dCTP}$ or $\left[{ }^{33} \mathrm{P}\right] \mathrm{dCTP}(2-5 \mu \mathrm{Ci} / 25 \mu \mathrm{L}$ reaction $)$ as the label (2). Following RAP-PCR, the amplified cDNAs were separated by electrophoresis on a 0.4 -mm-thick $4 \%$ polyacrylamide gel containing $7 \mathrm{M}$ urea. Because no suitable gel drying apparatus was available, a procedure for direct autoradiography of DNA sequencing gels was adapted to identify differentially expressed cDNAs. Before

Table 1. Yield of Re-Amplified DNA from Isolated Differentially Displayed cDNAs

\begin{tabular}{|lcc|}
\hline & \multicolumn{2}{c|}{ Yield (ng DNA/Reaction Volume) } \\
\cline { 2 - 3 } & Sample No. 1 & Sample No. 2 \\
\hline Eluate & 0 & $<20$ \\
Purified Eluate & 250 \\
Bands $(12-16 \mu \mathrm{L})$ were excised from the denaturing gel and eluted into $50 \mu \mathrm{L}$ \\
TE. The eluate was used directly for PCR or was purified using the Wizard PCR \\
Prep (Promega). Eluate $(2 \mu \mathrm{L})$ or purified DNA $(2 \mu \mathrm{L})$ was re-amplified in $50 \mu \mathrm{L}$ \\
PCR.
\end{tabular}

use, the glass plates of the electrophoresis unit (Sequi-Gen ${ }^{\circledR}$ Nucleic Acid Sequencing Gel; Bio-Rad, Hercules, CA, USA) were treated to facilitate gel handling. To increase adherence of the gel to the glass, the outer plate was treated with $0.5 \% \quad 3$-(trimethoxysilyl)propyl methacrylate and $0.3 \%$ acetic acid in $95 \%$ ethanol. The other plate was coated with Rain-X ${ }^{\circledR}$ (siloxane-based glass/ windshield treatment; Unelko, Scottsdale, AZ, USA) to increase separation of the gel from the plate (1). After electrophoresis, the Rain-X-treated plate was removed. The gel, on the outer electrophoresis plate, was covered with plastic wrap and autoradiographed for $24 \mathrm{~h}$ (33P-labeled DNAs) or $14 \mathrm{~h}$ ( ${ }^{32} \mathrm{P}$ labeled DNAs) at $-70^{\circ} \mathrm{C}$. Bands representing selectively expressed cDNA were excised from the gel $(12-16 \mu \mathrm{L}$ gel/band). DNA was eluted from the polyacrylamide into $50 \mu \mathrm{L}$ of TE buffer (10 mM Tris- $\mathrm{mCl}, \mathrm{pH} 7.5,1 \mathrm{mM}$ EDTA) for $1 \mathrm{~h}$ at $70^{\circ} \mathrm{C}$, followed by $8-20$-h incubation at $25^{\circ} \mathrm{C}$. DNA was either used directly for re-amplification under high stringency conditions, or it was purified from the eluate using Wiz$\operatorname{ard}^{\mathrm{TM}}$ PCR Prep according to the manufacturer's instructions (Promega, Madison, WI, USA) before use (2). DNA concentrations were determined fluorometrically using the TKO-100 Mini Fluorometer (Hoefer Pharmacia Biotech, San Francisco, CA, USA).

When DNA eluted from a differentially expressed band was used directly for re-amplification, yields of re-amplified cDNA were extremely low (Table $1)$. More often, no DNA at all was detected by agarose electrophoresis. Because the gel was not fixed or dried before excision of the DNA-containing band, we suspected that some component of the gel might inhibit PCR. To remove possible contamination, we purified the eluted DNA before PCR reamplification using the Wizard PCR Prep. As a result of this purification of DNA, yields of amplified products increased more than 10-fold (Table 1). For more than thirty re-amplification reactions, the yield ranged from 200 to 750 ng DNA per reaction.

To determine whether some component of the gel eluate was inhibiting PCR, the effect of a "blank" gel eluate and urea on amplification of a plasmid cDNA was tested. A high yield (850 ng) of amplified DNA was found for the control reaction (Figure 1, lanes 3 and 4$)$. In contrast, the presence of the gel eluate reduced the yield to less than

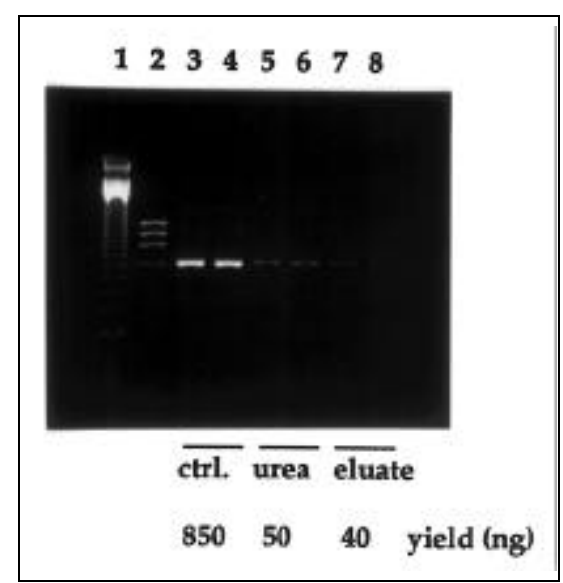

Figure 1. Inhibitory effect of urea on amplification of plasmid DNA. The cDNA insert of pGTBNR10 [370-bp maize root NAD(P)H:NR cDNA cloned into pGEM-T (Promega), $4 \mathrm{ng}$ ] was amplified in $50 \mu \mathrm{L}$ PCR using T7 and SP6 primers as described (6). Before PCR, plasmid was diluted to $2 \mathrm{ng} / \mu \mathrm{L}$ with water (lanes 3 and 4), 1.7 M urea (lanes 5 and 6) or blank gel eluate (lanes 7 and 8). The blank gel eluate was made by eluting $12 \mu \mathrm{L}$ of denaturing gel containing no DNA with $50 \mu \mathrm{L}$ TE. The migration of 123-bp DNA ladder and $\phi X 174$ DNA/HaeIII digest DNA standards (Sigma Chemical, St. Louis, MO, USA) are shown in lanes 1 and 2, respectively. 


\section{Benchmarks}

$5 \%$ of that of the control (Figure 1, lanes 7 and 8$)$. When urea $(1.7 \mathrm{M})$ was included in the DNA sample at a concentration designed to mimic that in the gel eluate, the yield of amplified DNA was reduced to about $6 \%$ of that of the control (Figure 1, lanes 5 and 6). Thus, the inhibitory effect of the gel eluate on PCR was largely attributable to urea present in the reaction $(70 \mathrm{mM}$ final concentration).

In conclusion, it is not necessary to fix and dry denaturing polyacrylamide/urea gels used in differential display or RAP-PCR. Consistently high yields of products were obtained during the high-stringency PCR, provided the DNA was purified before PCR. The results indicate that urea is a strong inhibitor of PCR. While fixing and drying polyacrylamide gels prevent urea contamination of the gel eluate, it is possible that purification of DNA eluted from fixed gels can also alleviate problems with inconsistent yields of DNA encountered during re-amplification. The advantage of the proposed modification in RAP-PCR protocol is that the cumbersome manipulations involved with fixing and drying the gel are eliminated, and a large gel dryer is not needed.

\section{REFERENCES}

1.Barnett, R.S. and J.N. Davidson. 1989 Coating sequencing gel plates. Focus 11:75.

2.Buchner, R. and D. McKenzie. 1995. Stratagene RAP-PCR kits for identifying differentially displayed gene transcripts. Strategies 8:12-14.

3.Liang, P., L. Averboukh and A.B. Pardee. 1993. Distribution and cloning of eucaryotic mRNAs by means of differential display: refinements and optimization. Nucleic Acids Res. 21:3269-3275.

4.Liang, P. and A.B. Pardee. 1992. Differential display of eukaryotic messenger RNA by means of the polymerase chain reaction. Science 257:967-971.

5.McClelland, M., F. Mathieu-Daude and J.
Welsh. 1995. RNA fingerprinting and differential display using arbitrarily primed PCR. Trends Genet. 11:242-246.

6.Sambrook, J., E.F. Fritsch and T. Maniatis. 1989. Molecular Cloning: A Laboratory Manual, 2nd ed. Cold Spring Harbor Laboratory Press, Cold Spring Harbor, NY.

7.Sharma, Y.K. and K.R. Davis. 1995. Isolation of a novel Arabidopsis ozone-induced cDNA by differential display. Plant Mol. Biol. 29:91-98.

8.Shen, R., Z.-Z. Su, C.A. Olsson and P.B. Fisher. 1995. Identification of the human prostatic carcinoma oncogene PTI-1 by rapid expression cloning and differential RNA display. Proc. Natl. Acad. Sci. USA 92:6778-6782.

9.van der Knaap, E. and H. Kende. 1995. Identification of a gibberellin-induced gene in deepwater rice using differential display of mRNA. Plant Mol. Biol. 28:589-592.

10.Welsh, J., K. Chada, S.S. Dalal, R. Cheng, D. Ralph and M. McClelland. 1992. Arbitrarily primed PCR fingerprinting of RNA. Nucleic Acids Res. 20:4965-4970.

This work was supported, in part, by USDA NRI Grant 9202391 to M.G.R. We thank C. Hsiao for helpful advice. Mention 


\section{Benchmarks}

of a trademark or proprietary product does not constitute a guarantee or warranty of the product by the United States Department of Agriculture and does not imply its approval to the exclusion of other products that may also be suitable. Address correspondence to Margaret G. Redinbaugh, USDA Agricultural Research Service, Forage and Range Research Laboratory, Utah State University, Logan, UT 84322-6300, USA.Internet: mredinba@cc.usu.edu

Received 20 May 1996; accepted 26 June 1996.

Premsyl Konecny and Margaret G. Redinbaugh ${ }^{1}$ Utah State University and ${ }^{1}$ USDA, Forage and Range Research Laboratory Logan, UT, USA

\section{Manual Microcolumn Chromatography for Sample Cleanup Before Mass Spectrometry}

BioTechniques 22:244-250 (February 1997)

Protein biochemistry has benefited greatly from the increasing availability of both matrix-assisted laser desorption ionization (MALDI-) and electrospray ionization mass spectrometers (ESIMS) due to their high sensitivity and tolerance to some commonly used buffers. However, analysis of biologically derived samples at sub-pmol levels often provides serious challenges, e.g., although MALDI-MS is more robust with regard to many buffers and other contaminants found in biologically derived samples than ESI-MS, many of these compounds result in reduced signal intensity and poorer quality spectra. Sample cleanup protocols have used simple rinsing of the crystallized sample (1), novel preparation of the metal surface with matrix $(11,12)$ or other materials $(4,5)$, or they have used a separate surface for cleanup/crystallization before attachment to the MALDI-MS probe $(3,13)$. However, another property of MALDI-MS that is not alleviated by these approaches is that of ionization suppression in peptide mixtures (2). To overcome this problem, the mixture has to be partially fractionated. In ESI-MS, this can be overcome by using capillary reverse-phase, high-performance liquid chromatography (RP-HPLC) before on-line mass analysis.

We are interested in the analysis of small quantities (low to sub-pmol) of both gel-separated samples as well as samples purified by other means. However, as the level of sample decreases, the relative amount of contaminants increases, which adversely effects both MS methods. Therefore, we sought to find a method for sample cleanup before MALDI-MS that would allow the following criteria to be met: (i) rapid, (ii) simple, (iii) cost-effective and readily available, (iv) compatible with low to sub-pmol sample quantities, (v) could allow partial fractionation, (vi) would not incur significant sample losses and (vii) could cleanup samples from a wide range of solutions. We found that guard columns that are used in conjunction with 0.3-mm RP-HPLC columns meet these criteria. We demonstrate the utility of this approach by subjecting protein digests to a range of different "contaminants" (or excipients) with MALDI-MS analysis of the samples.

Aqueous protein solutions of rabbit muscle phosphorylase $b$ and horse heart myoglobin (Sigma Chemical, St. Louis, MO, USA) were quantitated by amino acid analysis. Five microliters of endoproteinase Lys-C (LysC) $(5 \mu \mathrm{g} / 50$ $\mu \mathrm{L}$ water, Boehringer Mannheim, Indianapolis, IN, USA) were added to 95 $\mu \mathrm{L}$ of $20 \mathrm{mM} \mathrm{NH} \mathrm{HCO}_{3}(\mathrm{pH} 8.0) / 0.1$ $\mathrm{mM} \mathrm{CaCl} 2$ buffer containing protein at a final concentration of $5 \mu \mathrm{M}$ and digested for $15 \mathrm{~h}$ at $37^{\circ} \mathrm{C}$. One microliter of this digest was mixed with $3 \mu \mathrm{L}$ of water (control) or the following excipients: glycerol, urea, guanidine-HCl $(\mathrm{GuHCl})$, EDTA or Dulbecco's phosphate-buffered saline (D-PBS; Life Technologies, Gaithersburg, MD, USA).

Microcolumns from LC Packings (distributed by Western Analytical Products, Temecula, CA, USA) were $300 \mu$ m i.d. $\times 1$-mm $\mu$-Guard ${ }^{\mathrm{TM}}$ columns. The microcolumns were purchased packed with the following: 5 $\mu \mathrm{m} \mathrm{C} 8, \mathrm{C} 18, \mathrm{C} 18$ (300 ^ wide-pore) and Poros ${ }^{\mathrm{TM}} \mathrm{R} 1$ and R2. The inlet tubing was $2 \mathrm{~cm}$ of $1 / 16^{\prime \prime}$ o.d., $300 \mu \mathrm{m}$ i.d. Teflon ${ }^{\circledR}$ (TFE; PE Applied Biosystems, Foster City, CA, USA), and the outlet was $1 / 16^{\prime \prime}$ o.d., $0.005^{\prime \prime}$ i.d. PEEK (Red; Upchurch Scientific, Oak Harbor, WA, USA). The outlet tubing was shaved to yield a conical end to assist in droplet formation. The tubing was attached to the column with Lite-Touch ${ }^{\circledR}$ Ferrules for 1/16" o.d. tubing (Upchurch Scientific). The tubing was chosen to give the smallest dead volume and allow easy use of the required syringe. Solutions were introduced into the column with a $10-\mu \mathrm{L}$ Hamilton syringe with a fixed beveled needle and Chaney adaptor (Baxter Healthcare, Irvine, CA, USA). The standard protocol for sample cleanup was to apply the sample to the column (between 3 and $10 \mu \mathrm{L}$, including samples vacuum-concentrated from a larger volume) and to wash with 